\section{Bewitched by a computer}

\section{Simon Lavington}

The Soul of a New Machine. By Tracy Kidder. Pp.254. US ISBN 0-316-49170-5; UK ISBN 0-7139-1482-3. (Little, Brown/Allen Lane: 1982.) \$12.95, $£ 7.50$.

COMPUTERS are created by teams - for the simple reason that even the smallest of them is too complicated to be designed in a reasonable time by one person alone. This team approach is common to many other complex engineering projects, and yet a hint of sorcery does surround the birth of a new computer. In The Soul of a New Machine, Tracy Kidder examines this mystique through the eyes of a computer design team operating in the United States in the late $1970 \mathrm{~s}$.

The book is somewhat retrospective, for few computers are today things of mystery. Market forces and the increased use of design automation are producing a convergence of approaches amongst manufacturers. Standard computers are off-the-shelf items and it is only in the areas of very high performance or specialpurpose computers that there is much scope for engineering innovation. It has not always been thus. Not too many years ago every computer was special. They were special not only in the engineering sense but also because of the unexpected avenues they opened up for human endeavour. Man could comprehend machines which enhanced his physical strength, mobility or range of communication, but here was a new type of machine which cooperated with and enhanced his very thoughts.

Of course the difficulty was - and is that computers do not speak the same language or share the same preconceptions as human beings. The computer is simpler, faster, more rigorous, less forgiving than its designer and nowhere is this mis-match felt so keenly as during the testing of new hardware or software. Getting a computer to work properly - especially under commercial pressures - demands a particular kind of mental and physical stamina for which there are few parallels. There is all the difference in the world between thinking about a new computer and actually building one, though a result of modern design methodology has been to reduce the areas of uncertainty. A computer design team has thus to operate in an unusual environment and, until quite recently, the team morale was strengthened by the unspoken feeling that the members were in some way pioneers of a new age.

The Soul of a New Machine is something of a misnomer, for the book is really about the soul of the design team. Brought together and sustained by the god-like personality of their leader, the team is given the challenge of designing a relatively high performance machine within severe political constraints imposed by the company's top management. In describing this political background, $\mathrm{Mr}$ Kidder provides an interesting analysis of the minicomputer market at a time which saw the progression from 16-bit to 32-bit machines. In particular, the development of the Data General Company is charted with the financial precision of a business journal, and students of modern industrial development will find this very revealing. The machine itself remains in the wings for most of the story. It is in any case somewhat of a hybrid - an attempt to achieve large computer performance whilst maintaining compatibility with a small computer marketing base. Although by no means a technical landmark, the project does involve the solution of some unusual design problems and the emphasis on processing speed makes fault-finding the more difficult. Few hints are given about the precise tricks played by the engineers to obtain the performance they required, but this omission is perhaps just as well. Mr Kidder is not at home with computer terminology; his attempts to interpret the jargon for a lay readership are at times ungainly, and cognoscente will recognize instances where his simplifications are based on misconceptions.

Luckily, however, a precise technical understanding is not necessary for an appreciation of the book's underlying theme: the response of young engineers to stress. Mr Kidder's unease in some ways emphasizes the gulf between computer terminology and everyday language, a gulf which tends to place computer engineers apart from other mortals. The jargon, the project deadlines, the group pressure to work long and unsociable hours, the mental effort of pinning down faults from the most sketchy of clues -- it is no wonder the engineers become totally absorbed by their machine.

There is also a subtle yet pervasive managerial influence applied to the team. To most of the engineers this is their first chance to make a personal contribution to the design of a new computer and the team leader appears to exploit this. The ephemeral glory of "having your name on the machine" is offered only to those who are willing to devote their total waking hours to the project. As the project progresses, any lesser commitment becomes unthinkable by the young engineers themselves; peer pressure ensures finally that they are not so much enslaved as bewitched. Wives and families receive scant mention in the book, but they probably felt that the machine was being weaned on men's souls.

The story will ring true for anyone who has been involved in the design of a new computer, and yet these same readers will find $\mathrm{Mr}$ Kidder at times frustrating. This is because the tantalizing glimpses of engineering problems leave unassuaged a thirst for more detail. But if the book is thankfully - not a technical report, it is also not a novel. It fails to do justice to the dramatis personae; the character sketches dwell excessively on the scientific career of the team members and few of them emerge from the pages as flesh and blood. In a sense this criticism is unfair, since the book should be judged as a documentary which makes a successful attempt to bridge the gap between high technology and everyday experience. With computers, for better or worse, pervading every corner of society, such bridge-building books are badly needed.

Simon Lavington is a Senior Lecturer in Manchester, and author of Early British Computers (Manchester University Press, 1980). Computer Science at the University of

\section{Harvested thoughts}

Wolfgang Paull: I don't mind your thinking slowly: I mind your publishing faster than you think.

[Sir] Francis Galton: [Statistics are] the only tools by which an opening can be cut through the formidable thicket of difficulties that bars the path of those who pursue the Science of Man.

[Lord] Ernest Rutherford: If your experiment needs statistics, you ought to have done a better experiment

Michael Flanders: One of the great problems of the world today is undoubtedly this problem of not being able to talk to scientists, because we don't understand science; they can't talk to us because they don't understand anything else, poor dears.

Francis [Lord] Jeffery: 'Damn the Solar System. Bad light; planets too distant; pestered with comets; feeble contrivance; could make a better myself.'

Samuel Butler: We shall never get people whose time is money to take much interest in atoms.

[Lord] John [of Selmeston] Wilmot [Minister of Supply 1945-1947]: What I like about scientists is that they are a team, so that one need not know their names.

Victor Frederick Weisskopf: Science has become adult: I am not sure whether scientists have.

Leo Szilard: Don't lie if you don't have to.

Eric Temple Bell: The cowboys have a way of trussing up a steer or a pugnacious bronco which fixes the brute so that it can neither move nor think. This is the hog-tie, and it is what Euclid did to geometry.

These quotations are taken from Alan L. Mackay's delightful collection, Harvest of a Quiet Eye, first published in 1977 by The Institute of Physics. The book contains well over a thousand such aphorisms and quotations, and has just appeared in paperback, price $£ 3.95, \$ 9.95$. Hardback is $\mathbf{£} \mathbf{8 . 5 0}, \mathbf{\$ 2 2 . 5 0}$. 